\title{
COREOGRAFÍA DE LA EXPECTACIÓN, TONOS E INDICIOS MUSICALES \\ EN EL ENTREMÉS DE LOS INSTRUMENTOS
}

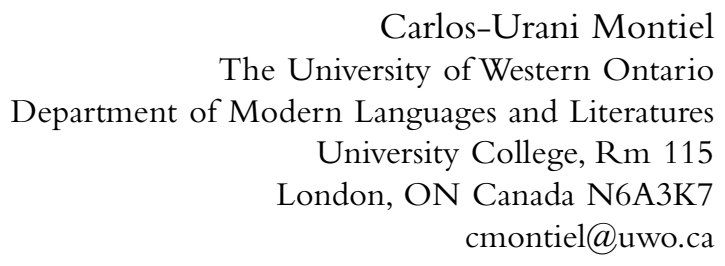

[Anuario calderoniano (ISSN: 1888-8046), 5, 2012, pp. 145-167]

«... que he de cantar afectos suspendidos ${ }^{1} »$

En el entremés calderoniano, publicado en Tardes apacibles de entretenimiento ${ }^{2}$, el vínculo entre la expresión musical y el estímulo de expectativas en el auditorio sucede a partir de los tonos y de las asociaciones entre los instrumentos y sus diferentes usos ${ }^{3}$. En el siglo XVII el

${ }^{1}$ Calderón de la Barca, En la muerte de la señora doña Inés Zapata, v. 4.

2 Madrid, 1663.

${ }^{3}$ Por tono me refiero a piezas breves cantadas y acompañadas por música. Más adelante regresaré a este punto. 
mismo dramaturgo alude a la moción de afectos En la muerte de la señora doña Inés Zapata (1628). Calderón dedica las elegías a doña María Zapata - hermana de la difunta - a quien le pide que lo escuche «no por ser la postrera / que he de cantar afectos suspendidos», sino por lo lastimoso de la voz del yo lírico (vv. 1-7), que expresará por medio del canto cómo sus pasiones han sido arrebatadas y detenidas por lo extraño del suceso ${ }^{4}$.

La coreografía - acomodo o ensamble- de las expectativas en el ámbito dramático incita y controla las respuestas emotivas del auditorio a través de los indicios musicales, sean estos sonoros como los tonos, o físicos como los propios instrumentos. Cuando el espectador escucha secuencias sonoras y las identifica por conocimiento previo o por la repetición en la misma estructura de la composición, puede anticiparse a las secuencias siguientes. Este fenómeno musical también ocurre a nivel del argumento de la obra. Cuando el auditorio reconoce la melodía o la letra de alguna canción, adquiere un punto de referencia dentro de la trama, así como un sentimiento de seguridad, ya que lo que aparenta ser anticipable reduce incertidumbre. La correcta identificación de un indicio musical simula también el conocimiento asociado a éste, como por ejemplo, el asunto trágico de un romance o el toque de trompeta y chirimías de una entrada solemne. A lo largo del artículo detallaré cómo es que los tonos e indicios musicales en el Entremés de los instrumentos crean el efecto de predicción y cómo éste puede ser roto, generando sorpresa y dejando al descubierto el enlace entre las emociones y la música.

Para lo cual el ensayo está dividido en dos secciones; la primera retoma un par de teorías provenientes de la neurociencia, la musicología y las ciencias de la conducta. Una de ellas sostiene que la conciencia individual —utilizada en el sentido definitorio de identidad que le dio John Locke en $1694^{5}$ - , se codifica en sistemas simbólicos

4 Suspender: «significa también arrebatar el ánimo, y detenerlo con la admiración de lo extraño, o lo inopinado de algún objeto o suceso" (Aut). Casares Rodicio, 1977, p. 58, opina que la Iglesia lograba transportar al creyente en los solemnes ritos por medio de música y canto, y "colmaba la esfera de lo emocional con sus cualidades dramáticas y expresionistas».

5 «Porque, como el tener conciencia siempre acompaña el pensamiento, y eso es lo que hace que cada uno sea lo que llama sí mismo, y de ese modo se distingue a sí mismo de todas las demás cosas pensantes, en eso solamente consiste la identidad per- 
que comparten los miembros de una comunidad a través de su distribución en redes colectivas. Son varios los investigadores que sustentan esta postura y de entre de ellos destacan Antonio Damasio, Edwin Hutchins y Merlin Donald. La otra teoría pertenece al musicólogo canadiense David Huron, quien describe una psicología de la expectación en relación directa con la música. Él explica que al escuchar el flujo de sonidos tendemos a configurar totalidades, lo que implica la realización de predicciones sobre lo que sonará después. La segunda sección del artículo verifica la aplicación de estas contribuciones al análisis de Los instrumentos a partir de sus alusiones verbales ${ }^{6}$. Si la música entretiene y promueve la participación del oyente, las secuencias y contrastes en su composición mueven los afectos y consiguen la atención y sorpresa del auditorio.

\section{COREOGRAFÍA DE LA EXPECTACIÓN}

Mencionamos que el reconocimiento de una canción recrea en el oyente las asociaciones ligadas a esta — de entre las que destacan las respuestas emocionales-, generando así una serie de expectativas. Esta práctica es en realidad un proceso que ejercita la habilidad para imaginar eventos futuros, preparar reacciones motoras, simular realidades para después aproximarlas a posibles $\operatorname{contextos}^{7}$, anticipar o predecir los siguientes sonidos y responder física y mentalmente conforme a la expectación inicial. ¿Pero en qué consiste la construcción de expectativas y qué sucede cuando éstas fallan? ¿Cómo es que el flujo de sonidos logra moldear las experiencias emotivas de un auditorio? ¿Y en dónde se encuentra la información representacional de sonidos abstractos que por principio son no-representacionales?

sonal, es decir, la mismidad de un ser racional» (Locke, Ensayo sobre el entendimiento humano, 1999, p. 318).

6 «In the absence of adequate musical documentation, we must engage in something resembling musical speculation, with all its pitfalls in an attempt to represent in our mind's ear the sound of the autos as we read them» (Pollin, 1973, p. 367).

${ }^{7}$ El físico norteamericano Heinz Pagels (1988, p. 88) nos recuerda que una buena simulación, sea un mito religioso o una teoría científica, nos da un sentido de manejo sobre nuestra experiencia. Representar algo simbólicamente, como cuando hablamos o escribimos, es, de alguna forma, hacerlo propio. 
Los especialistas en ciencias cognitivas han estudiado la correlación neuronal de las emociones sin poder dar una explicación clara de cómo y por qué las sentimos. Lo que buscan son las bases racionales de la emoción y de la creación artística así como el substrato emotivo del pensamiento racional. El neurólogo Antonio Damasio afirma que el influjo de los sesgos emocionales interviene en la toma de decisiones, contempla paisajes futuros, y posee un sentido de comunidad, convención social y principio moral. Su investigación parte de la premisa de que los fenómenos mentales «sólo se los puede entender totalmente en el contexto de un organismo que interactúa con un medio ambiente» ${ }^{8}$.

Así, los niveles neurales que regulan el procesamiento de las emociones y los sentimientos mantienen una relación directa con la creatividad y la conducta social. El sistema nervioso periférico, por ejemplo, ingresa señales relativas del medio ambiente con el fin de regular al organismo. Debido a que el filtro corporal coincide temporalmente con la percepción o evocación de otra cosa que es ajena al cuerpo - como el tañido de una guitarra-, los sentimientos califican a ese estímulo y generan emociones. "Sentir una emoción», expone Damasio, significa vincularla «con la cosa que la estimuló, tomar conciencia del nexo entre objeto y estado emocional físico", con lo cual la conciencia se extiende y obtiene una capacidad de protección ${ }^{9}$. Conocer ese vínculo permite anticipar acontecimientos, formular expectativas o predecir / reducir probabilidades. Estar conciente de las emociones ofrece una respuesta flexible basada en la historia particular de las interacciones con el medio social.

El proceso descrito por Damasio que afecta y crea un «estado corporal emocional» consiste en la evaluación cognitiva de los contenidos del acontecimiento y la formación de «imágenes mentales de los aspectos escénicos principales». Tales representaciones se organizan en

${ }^{8}$ Damasio, 1996, p. 17.

${ }^{9}$ Damasio, 1996, p. 157. La ampliación o extensión de la conciencia se explica por la adquisición de un pasado, por la posibilidad de ser registrada y por la capacidad de anticipación, ya que permite reducir incertidumbres en entornos semejantes debido al aprovechamiento de experiencias previas. «Extended consciousness is, then, the capacity to be aware of a large compass of entities and events, i.e., the ability to generate a sense of individual perspective, ownership, and agency, over a large compass of knowledge than that surveyed in core consciousness» (p. 198). 
diferentes capas sensoriales, como la auditiva, y responden generalmente al conocimiento adquirido por el individuo. A esta categorización le sigue una respuesta involuntaria a las señales derivadas de las imágenes; se activan núcleos del sistema nervioso; se mandan señales al sistema motor y se produce un cambio en el estado físico; finalmente, el sistema endocrino y varios neurotransmisores logran activarse y completar el ciclo de una emoción ${ }^{10}$. Los mecanismos neurales que sostienen este proceso pueden obedecer a un diseño formal que, sin embargo, requieren de la mediación de la sociedad para llegar al producto final.

Así que una vía para comprender la activación de circuitos neurales tras estímulos externos ha sido la distribución de la cognición humana en el entorno socio-cultural, por lo que a finales del siglo pasado varios científicos se enfocaron en redes sociales que se extienden más allá de un cerebro y que almacenan unidades de información en soportes externos. El profesor Edwin Hutchins fue de los primeros en estudiar la cognición distribuida, la cual se enfoca en el conocimiento que una persona debe poseer para tomar parte activa en un sistema cultural. Esta postura va en contra de la asunción de que el conocimiento se localiza dentro del individuo, dejando fuera cualquier influjo del medio ambiente, y sostiene que la cultura no es una colección de cosas tangibles o abstractas (conocimiento, creencias, arte, herramientas, costumbres, etc.), sino que es un proceso adaptativo. La cultura es para Hutchins un proceso de la cognición humana que ocurre tanto dentro como fuera de las personas, en el que nuestras prácticas cotidianas se desarrollan y evolucionan ${ }^{11}$.

El óptimo funcionamiento de una comunidad consiste en la regulación del consumo de energía y en la obtención del mayor pro-

${ }^{10}$ Una emoción queda definida por la combinación de un proceso de valoración mental con respuestas que emanan de las imágenes mentales, innatas o adquiridas, dirigidas al cuerpo principalmente, pero también al cerebro mismo, con el resultado de cambios mentales y de comportamiento (Damasio, 1996, pp. 159-164).

${ }^{11}$ Hutchins, 1995 , p. 354. Cognition in the Wild, le da un contexto social a la actividad cognitiva; el título designa que las actividades mentales deben ser estudiadas en su hábitat natural; o sea, en uno cultural, donde la cognición humana interactúa con un medio ambiente rico en recursos organizativos. Anteriormente Clifford Geertz, desde la antropología, había denominado a este fenómeno, «outdoor psychology» (1983, p. 151). 
vecho del entorno físico. Para que esto se cumpla existen factores de organización que producen propiedades específicas del grupo, las cuales difieren considerablemente de las características particulares de cada uno de sus elementos. Lo mismo sucede en el ámbito cognitivo; es decir, un grupo tiene propiedades cognitivas que no son predecibles por el conocimiento de las propiedades de cada sujeto. Entonces, los medios de representación externos son los que regulan la actividad individual con el sistema entero. Esta experiencia se codifica simbólicamente en diferentes registros (sonoros, escritos, pictóricos, etc.), que tienen el potencial de ser transmitidos a otros individuos por medio de varios mecanismos —imitación, enseñanza-aprendizaje, memoriaexperiencia-, que consiguen producir y reproducir la organización del sistema cultural.

Merlin Donald, profesor de psicología, comparte la idea sobre la distribución en redes de conocimiento y sostiene que las habilidades simbólicas evolucionan en el exterior (de afuera hacia adentro). El origen y perfeccionamiento de cualquier lenguaje se localiza en el seno de las comunidades cognitivas; específicamente, en la concepción que poseen de sí mismas como grupo. Donald propone un recorrido evolutivo de la conciencia en donde el punto más alto se distingue por parámetros temporales que permiten hacer uso de la memoria colectiva para después supervisar una nueva tarea o evaluar un estado futuro $^{12}$. El desarrollo de la conciencia provee el fundamento de la cultura; mientras que esta, a la inversa, facilita los mecanismos y medios con los que el grupo se reconoce y distingue de los demás. Esto implica una coevolución entre el sistema cultural y el cerebro, diseñado para asimilar el saber cómo de cada actividad y para asumir la existencia de un mecanismo de almacenamiento en el exterior. Donald explica que la memoria externa, definida como un sistema de almacenamiento y recuperación de experiencia y conocimiento que permite, por un lado, vaciar ("off-loading») información crucial que replica a la misma cultura; y, por otro, estructurar una teoría sobre la evolución de los lenguajes ${ }^{13}$, entendidos como capacidades emergen-

12 Donald, 2001, pp. 11 y 194.

13 Donald, 2001, p. 309. Además, él señala que «human culture started with an archaic, purely non-linguistic adaptation, and we never had to evolve an innate brain 
tes sólo a nivel de grupo y como productos sociales distribuidos a través de la interacción de varias mentes.

Ahora bien, la naturaleza secuencial del discurso musical es una característica definitoria de su lenguaje. La música se construye con secuencias sonoras, de tal forma que el reconocimiento de patrones es vital tanto para quienes la componen como para quienes escuchan los sonidos. La detección de patrones implica la proyección de lo que está por venir; esta actividad está en la raíz del pensamiento y también es la base del entretenimiento ${ }^{14}$. Las secuencias sonoras más esenciales, además de producir experiencia y haber absorbido conocimiento del mundo exterior, están asociadas a emociones que logran ser evocadas en el oyente. La música impulsa la imaginación y el reconocimiento de patrones; asimismo, entrelaza rituales con situaciones simbolizadas y estados emocionales.

El vínculo entre la música y las emociones tiene una amplia tradición filosófica y literaria. Ya a mediados del siglo XVI y en el contexto hispano, fray Juan Bermudo enunciaba los tres tipos de beneficios que vienen de la música: «los bienes de fortuna son dineros, y otras riquezas; los corporales salud, alegría, y cosas a este tono; los espirituales son las virtudes» ${ }^{15}$. Basta aquí un par de testimonios más de finales del XVII: uno del autor estudiado quien asienta que el objeto de la músi-

device for language per se or for many other of our unique talents, such as mathematics, athletics, music and literacy» (2001, pp. 11-12).

14 Nuestro cerebro posee una gran habilidad para diseñar secuencias intrincadas y refinadas de movimiento para después ejecutarlas. Desde la neurofisiología, William Calvin opta por llamar al hombre Homo seriatim y reflexiona sobre la maquinaria que articula diferentes secuencias: «Does it account for our self-consciousness as we see ourselves poised at the intersection of two plausible scenarios, choosing between different futures?» (1989, p. 279). Mark Turner, científico cognitivo, confirma que «composing or recognizing a musical phrase, speaking or listening to a sentence, and telling or understanding a story are all examples of our ability to recognize or execute a sequence that counts as a whole» (1996, p. 18). El papel de la memoria en la ordenación de secuencias es clave en el procesamiento de emociones que la mente conciente realiza en su preocupación por el yo dentro de una comunidad. "Una mente consciente es un proceso mental simple que está siendo informado de sus relaciones simultáneas y en curso con objetos y con el organismo que la alberga» (Damasio, 2005, p. 204).

15 Bermudo, Comienza el libro primero de la declaración de instrumentos, fol. 26v. 
ca es "suspender el espíritu a cláusulas sonoras» ${ }^{16}$; y otro valioso no solo por señalar el movimiento de afectos, sino por la respuesta del oyente. En el ensayo «Sobre el origen de las cosas», Gottfried Leibniz realiza una analogía de los sentidos: lo que los ojos descubren en una pintura, los oídos en la música.Y enseguida añade que:

The most illustrious composers often mingle discords with their harmonies in order to excite and pique, so to speak, the listener, who, anxious as to the outcome, is all the more pleased when soon all things are restored to order ${ }^{17}$.

Recientemente, David Huron ha descrito el funcionamiento de un conjunto de mecanismos psicológicos capaces de evocar respuestas emotivas particulares a partir de estímulos sonoros. Desde su punto de vista, tanto la biología como la cultura contribuyen al fenómeno subjetivo de las experiencias humanas y para demostrarlo se apoya en las artes escénicas que alcanzan efectos emocionales específicos a través de representaciones estereotipadas (con máscaras, gestos, posturas fisicas, etc.); sin embargo, Huron se centra en la música por no ser un arte representacional en la forma que lo son la pintura o la escultura. Según él, la principal fuente de contenido emocional de la música proviene de una coreografia de la expectación trazada por el compositor, en la que éste decide si frustra nuestra expectativa, la retarda, o simplemente ofrece lo que espera el auditorio.

En este sentido, en Sweet Anticipation leemos que la expectación es una adaptación biológica con estructuras psicológicas especializadas y un largo camino evolutivo, pero que al mismo tiempo, la cultura moldea el ambiente en donde las expectativas son adquiridas y aplicadas. La capacidad de formar expectativas adecuadas sobre eventos futuros otorga importantes ventajas biológicas; es una función mental adaptativa que le permite al organismo prepararse para una percepción y acción apropiadas. Las emociones amplifican motivaciones, persiguen comportamientos adaptativos, estimulan la formación de predicciones, promueven la preparación para eventos venideros e incrementan la

16 Calderón de la Barca, Deposición a favor de los profesores de la pintura. Sobre la filosofía de la música a la que estuvo expuesta el dramaturgo madrileño, ver el estudio de Jack Sage, 1973, pp. 209-212.

17 Leibniz, «On the Ultimate Origin of Things», p. 111. 
probabilidad de resultados favorables. El propósito biológico de las expectativas es preparar al organismo - cuerpo y mente- para cambios futuros. La formación de expectativas minimiza el consumo de recursos metabólicos, ya sea a nivel de esfuerzo físico o de foco de atención ${ }^{18}$. El incremento o inhibición de ambos niveles depende tanto de la incertidumbre del medio ambiente (el qué y el cuándo algo pasará), como de la capacidad de anticipación.

En la música el contexto para la predicción de sonidos futuros también es dominado por normas culturales distribuidas en el medio de interacción. Los métodos de adquisición de este tipo de conocimiento pueden ser por inducción (observación o la experiencia) y por deducción (proposiciones y axiomas). El razonamiento inductivo puede fallar, ya que depende de la interpretación; sin embargo, la experiencia es fuente de aprendizaje y se verifica por medio de inferencia estadística. Para Huron, uno de los descubrimientos más importantes en el aprendizaje auditivo ha sido que los oyentes son sensibles a las probabilidades de diferentes patrones y eventos sonoros, y que esas mismas probabilidades son usadas para formar expectativas sobre el futuro $^{19}$. Según nuestra experiencia un amplio rango de situaciones se asocia con los estímulos que provocan emociones; entonces, la reacción se filtra por una valoración reflexiva que en ocasiones parece inmediata o innata, pero que ha sido adquirida tras una exposición prolongada a estímulos recurrentes.

\section{TONOS E INDICIOS MUSICALES EN LAS TABLAS}

Tono, tonadilla, tonadas humanas, designan en el siglo XVII a piezas breves en donde el canto es acompañado por música. El calificativo de humana se refiere al empleo de la voz, tal y como lo define la primera acepción del Diccionario de autoridades: tono es «el sonido que hace la voz, cuando se habla, o se canta», y más adelante especifica que «se llama también la canción métrica para la música compuesta de varias coplas». Covarrubias indica que el tono es el «sonido o acento» que los músicos dividen, "considerando lo que sube, y lo

18 Ver Huron, 2006, pp. 2-4.

19 Huron, 2006, p. 60. 
que baja el canto llano", por lo que se dice "entonar, cantar a tono»; una tonada es «el aire del cantarcillo vulgar... que hoy usan los músicos de guitarra» ${ }^{20}$.

Al contrario de un romance o villancico, que son formas literarias para cantar, la tonada no se define por un esquema métrico, sino que designa la música de cualquier "cantarcillo». La distinción entre las palabras villancico y romance va desapareciendo y la última se convierte en un sinónimo de tono, solo, tonillo, chanzoneta, letra, baile, o jácara. En 1665, por ejemplo, el manual de Rítmica, de Juan Caramuel (segunda parte del Primus Calamus), explica que «si a un poema, que sería un Romance, se le añade música y se hace que cuente una historieta, será una Xácara» ${ }^{21}$. En general, todos los términos señalados se refieren a una canción profana escrita para una (monodia) o cuatro voces, con o sin acompañamiento instrumental.

El agrado del público ante las composiciones musicales y la danza que ameniza las piezas en el escenario se concretó en el teatro breve, compuesto por música y baile. Los tonos que se imponían sobre el bullicio son para el hecho teatral otra forma de entretenimiento a la que el espectador accedía por medio del canto, la música y la coreografia. El entremés de "Los instrumentos» genera y confirma expectativas que son transmitidas a través de un breve repaso de personajes, tonos e instrumentos que ensamblan un ambiente sonoro de variados y complejos recursos, del cual el auditorio hace uso en la totalidad del espectáculo.

En esta pieza Calderón realiza una tipología de instrumentos musicales. Los elementos de composición del entremés (escarnio antisemita, contexto de latrocinio, baile y música como tema central) mue-

${ }^{20}$ En el tratado El porqué de la música, Andrés Lorente confirma que «tono es un conocimiento, en cualquier cantoría, de principio, medio, y fin, haciendo juicio del tono que es, por lo que sube y baja en el discurso de su composicion» (1672, fol. 28).

21 «En árabe y en hebreo hay una raíz común, zacar, que significa acordarse, de la cual se deriva zácara, memoria, conmemoración, narración». Y a esto Caramuel recomienda que «para cantar estos poemas con suavidad, las notas enarmónicas deben ser pocas y fáciles, acomodadas al impulso de la voz» (Primer cálamo, p. 139). No estamos aquí en la órbita del «estilo antiguo» (obras polifónicas en latín), sino las escritas en romance, "pronto delimitadas a las celebraciones del Corpus, Navidad y otras pocas fiestas» (López Calo, 1977, p. 155). 
ven a risa y buscan la aprobación popular. Evangelina Rodríguez y Antonio Tordera, sus editores contemporáneos, informan que «la importancia de las canciones y de la coreografia de este entremés configuran como estructura musical el núcleo del mismo»"22. Aquí, los personajes cantan y bailan al tiempo que presentan en el escenario un desfile de aparejos reconocibles para los espectadores, a quienes se les incita a asociar el canto del personaje respecto al instrumento que interpreta y, sobre todo, a las funciones o contextos sociales en donde éstos suenan.

La trama y anécdota del entremés, enmarcado en el contexto festivo del Corpus, son sencillas. Los ladrones Torrente, Cortadilla y Mostrenca insultan al vejete Chilindrina (o Chilindrón), quien da cuenta del pleito a Lorenzo mientras que defiende su oficio y experiencia en el hurto. Tras el juego de pullas entran a escena dos alcaldes con intención de prender a los ladrones, acomodados en círculo al fondo del tablado. El intercambio de insultos con el que inicia la pieza, tiene un paralelo en la conversación de los alcaldes, ya que Rechonchón se aparta de su tarea y enfrenta a Oruga por no tener credo en su linaje (v. 45). En tanto, Torrente advierte: "que nos han sentido, los alcaldes de este pueblo» (vv. 62-63) y Chilindrina pide calma, resolviendo que él los sacará del aprieto. Enseguida, la acotación indica: «Cantan y bailan y el Alcalde Rechonchón con ellos)". Cuando Oruga ordena: "Vengan a la cárcel presos», Chilindrón ya ha pedido que toquen los instrumentos, fingiendo ser de una compañía teatral; así que Rechonchón se opone a la orden, intercede a favor de ellos, ya "que son ladrones del cielo", y se vuelve contra su colega: "primero os prenderé a vos» (vv. 83-90). Además de ser asido y de recibir los motes de cristiano nuevo, Oruga también señala las excusas del Concejo para no efectuar las fiestas ${ }^{23}$. No obstante las «mil faltas en la Villa» (v. 118),

22 En Calderón de la Barca, Los instrumentos, p. 226. En adelante citaré esta edición (1982) con el número de verso a renglón seguido. Henry W. Sullivan ha expuesto una crítica a este trabajo editorial (1985).

${ }^{23}$ Lobato, 1989, p. 652. La misma María Luisa Lobato enlista las pullas antijudías de nuestro entremés (p. 317). En el registro burlesco es amplia la tradición antisemita. Eugenio Asensio menciona dicho motivo en la serie dramática de alcaldes encontrados (ilustrado en Quiñones de Benavente), en donde los dos presumen ser cristianos y disputan que su abolengo es «tan rancio como el tocino añejo» (1971, pp. 149-155 y 164). 
Rechonchón asienta que "fiesta ha de haber, compañero» (v. 136) e inicia una secuencia de inversión en donde él ira despojando a los demás de sus instrumentos para con éstos diseñar su atuendo. Finalmente, los ladrones reconocen el robo y fallo de sus propósitos: «Hurtar pensamos al pueblo / y él nos hurto sin pensar» (vv. 226-227). A esto le sigue el acostumbrado desenlace festivo con canto y baile de las piezas breves.

Existen pistas con las que el entremés se incorpora a una tradición cómico-burlesca que promueven y manifiestan la participación de la experiencia del público, quien puede identificar a la «Venta de Viveros» (v. 5) como un lugar no recomendable. Dicha mención, más que una localización específica en el mapa es un vínculo a la geografia simbólica en donde cada coordenada — como el «letuario de naranja» (v. 14) para «las mañanas de invierno» de las letrillas de Góngora-, representa una referencia a disposición de los autores que recurren a éstas de forma aislada pero sin trazos del contexto al que pertenecen.

El experimentado Chilindrina es el orquestador de Los instrumentos. Desde sus primeras intervenciones realiza juegos de palabras que precisan del lenguaje de germanía y ensalzan el arte de robar. Su «Y tú, y tú, turrutú, desde la cuna / miente lo que le toca a cada una» (v. 15) adelanta los componentes espectaculares que lo constituyen como personaje entremesil: coreografia, ritmo y música. En la defensa que enuncia a su favor él cuestiona que:

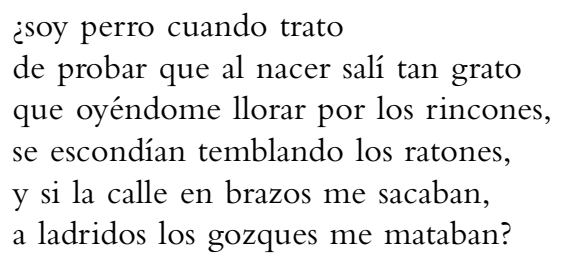

(vv. 17-22)

Las tres ediciones modernas copian "grato", pese a que el contexto semántico (perros, ratones, ladridos) sugiere que la palabra correcta es "gato", que también tendría significado dentro del vocabulario de germanía. Rodríguez y Tordera insinúan una posible errata ${ }^{24}$, pero

${ }^{24}$ Ver Calderón de la Barca, Los instrumentos, p. 229. Las otras dos ediciones son las preparadas por Díez Borque, 1983, p. 150; y Lobato, 1989, p. 307. 
otra interpretación ubica de lleno al auditorio en el juego de expectativas que los haría adelantarse al ritmo acentuado de los versos para después romper con su predicción y ofrecer un "grato", tan fuera de sentido como lo ridículo del personaje que lo expone.

En contraposición al ritmo e ingenio de Chilindrón, la entrada de los alcaldes rompe la consonancia de los endecasílabos en silva que venían sosteniendo los ladrones. En su primera intervención Rechonchón interrumpe la rima en pareados con la que su compañero avisa la presencia de los otros y le pregunta: "Oid, alcalde Oruga, y ¿con qué hurtan?» (v. 39), rompiendo la simetría de los diálogos. Lo mismo sucede a la postre en la defensa de Oruga contra los ataques de Rechonchón: «Sois un puerco y ipor Cristo!, / que a bocados os coma si me acerco" (vv. 59-60), provocando ahora una rima interna que afecta el ritmo de su arenga.

Es así que el canto y el baile son la respuesta de Chilindrón cuando él y los suyos son sentidos: «Decid a la compañía / que toquen y tañan los instrumentos, / y todos alegres, gustosos, contentos» (vv. 8284). La orden del experimentado ladrón alude a la tradición de contratar compañías teatrales para su concurso en las celebraciones litúrgicas. Esto queda confirmado cuando Oruga los interroga acerca de su oficio: «¿De qué vivís?», y la noble compañía contesta:

$\begin{array}{ll}\text { Chilindrón } & \begin{array}{l}\text { De vender } \\ \text { danzas, bailes, instrumentos }\end{array} \\ \text { Torrente } & \text { Cascabeles, campanillas... } \\ \text { Cortadilla } & \text { Castañetas, embelecos... } \\ \text { LORENZO } & \text { Sonajillas, silbatillos... } \\ \text { MostrenCA } & \text { Arpas, guitarras, panderos... }\end{array}$

(Hacen la reverencia cantando todos, y el alcalde responde cantando, haciendo la reverencia y quitándose la caperuza.)

25 Rodríguez y Tordera distinguen danza / baile en el contexto de la época «por el carácter más mesurado, elegante y cortesano de la primera y el valor más popular del segundo» (Calderón de la Barca, Los instrumentos, p. 232). 
La lírica cantada y los instrumentos han sido llamados a escena. Sólo resta hacer explícito el contexto de la representación y a una voz, Todos: «En esta fiesta del Corpus» (v. 100). Lo cual es digno de notar, ya que es probable que el tiempo y el espacio de ficción - el representado en las tablas- haya coincidido con los del espectador (un ambiente festivo de entremés y mojiganga) en el que Rechonchón, desde el escenario, pide que "Oremos» ${ }^{26}$ y afirma su cometido de organizar la festividad religiosa más importante de la época, «que so el festero, / he de her al señor San Corpus / lo que no vieren los ciegos» (vv. 103-105). El alcalde da inicio a los preparativos a pesar de que no haya una blanca en el pueblo, como puntualiza Oruga. Rechonchón pregunta a la compañía si «¿Tenéis comedia?», y recibe por respuesta: «Pues no, / autos», refiriéndose a los sacramentales, más propios para la fecha; sin embargo, él no los quiere y los rechaza "por que aquí al alcalde [Oruga] / le sobran los de Toledo» (vv. 106-109); es decir, los autos de fe tan en boga por el Tribunal del Santo Oficio toledano.

Comienza el baile y la presentación de las máquinas ${ }^{27}$. La acotación indica con precisión el acomodo de los personajes: «Van pasando por detrás de Rechonchón, con todos los instrumentos y él va volviendo la cabeza a una parte y otra». Hay que señalar que la misma postura del alcalde durante este primer y breve desfile (que va de los vv. 140-145), indica una actitud de expectación y sorpresa. Estos cinco versos son una rápida sucesión de ladrones — ahora músicos asociados a un instrumento y a una danza- que finaliza con la interrupción a gritos de Rechonchón: «iJesús, que me ahogo en danzas!» (v. 146).

El segundo desfile constituye en sí un giro grotesco en la acción del entremés (vv. 147-198) y es la secuencia antes aludida en donde los ladrones serán robados por el alcalde. El nuevo recorrido de aparejos musicales consta de la entrada a escena de un personaje que canta, baila y toca un instrumento hasta que Rechonchón lo arrebata y

26 Este recurso de integración del pueblo feligrés a la celebración oficial de la Iglesia, así como la función del texto cantado en la fiesta sacramental han sido expuestos con erudición por Díez Borque, 1983, pp. 39-70.

27 «Instrumento. Se llama en la Música cualquier machina y artificio hecho y dispuesto para causar harmonía, o con diversidad de cuerdas, dispuestas y templadas proporcionalmente $[\ldots]$ o con la compresión del viento $[\ldots]$ o mediante golpe o pulsación» (Aut.). 
va colgándolo de su cuerpo; es decir, una serie de quitar y ponerse (como marcan las acotaciones). En mi opinión lo realmente importante del «uso metonímico de danza por el instrumento correspondiente» ${ }^{28}$ y de lo cómico del vestido del alcalde, no es la mera acción entremesil, sino las asociaciones trazadas entre los instrumentos, la forma de tocarlos, los personajes que los usan y los actos sociales a los que acompañan ${ }^{29}$. Veamos.

La campanilla está vinculada a la "danza sacristana» (v. 139), ya sea porque la campana sirve "para llamar los fieles a la Iglesia» o porque en la Germanía, campana es «la saya y basquiña de la mujer» y un sacristán «se llamaba antiguamente una ropa interior, que usaban las mujeres, con unos aros de hierro pendientes de unas cintas, que se ataban a la cintura» ${ }^{30}$. Al canto de Lorenzo lo acompaña su instrumento:

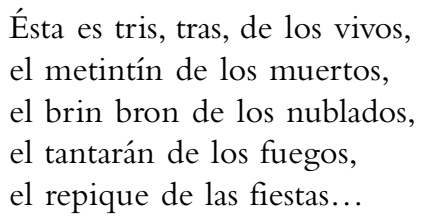

(vv. 147-151)

Es probable que la connotación negativa de las palabras muertos, nublados y fuegos, remita al hecho de que «las campanillas estuvieron muy en uso entre los antiguos hebreos, llevándolas puestas como adorno en los vestidos los sacerdotes ${ }^{31}$. Ante los sonidos onomatopéyicos de las vibraciones de la campana, el alcalde pide que paren, acusa a Lorenzo de hablador y, especifica la acotación «Quitale la campanilla y pónesela».

Cortadilla trae las castañetas, las cuales están relacionadas a la «danza gitanil» (v. 141). Ya Cervantes había expuesto dicha conexión en su

28 Además de este apunte, Rodríguez y Tordera nos recuerdan el proceso inverso de un personaje vestido de instrumentos al que se los arrebatan progresivamente en el Baile de la casa de amor (Calderón de la Barca, Los instrumentos, p. 238).

29 Huron, 2006, p. 270, señala que las sorpresas son mejor evocadas cuando el músico establece un contexto que las enmarca. Esto se consigue con elementos no sonoros, como vestimenta, escenografia, etc.

30 Campana (Aut.) y sacristán (Aut.).

31 Pedrell, Diccionario técnico de la música, p. 63. 
narrativa: «de entre el son del tamborín, y castañetas, y fuga del baile salió un rumor que encarecía la belleza, y donaire de la Gitanilla, y corrían los muchachos a verla, y los hombres a mirarla» ${ }^{32}$. Aunque la castañeta, también llamada castañuela, es «dama de las Cortes» ${ }^{33}$, sobresale su carácter típicamente popular:

labradora de los pueblos,
de las jácaras, cosquillas,
de las bodas, instrumentos,
de las comedias, alivio...

(vv. 155-159)

Rechonchón enfada nuevamente, pero Cortadilla continúa muy a cuento: «Y gracejo / de los tonos y bailes», hasta que lo despojan del instrumento de percusión. Por lo general el repique de las castañetas corresponde más a los pasos del bailarín que a la melodía de la música, y de ahí que sirvan para «acompañar el tañido de algún baile español» ${ }^{34}$.

Mostrenca porta los cascabeles asociados a su tamaño grueso. «De cascabel gordo» es un "apodo que se da, y dice de las personas que son ordinarias, y parecen rústicas en el trato, chanzas y gracejos», como los que "se disfrazan de botargas» $(A u t)^{35}$. Según Juan Esquivel Navarro y sus Discursos (Sevilla, 1652), «la danza de cascabel, es para gente que puede salir a danzar por las calles», en oposición al «danzado de cuenta» que «es para Príncipes, y gente de reputación, como lo tengo dicho, y probado en este Tratado» ${ }^{36}$. Mostrenca presenta al antiquísimo instrumento como:

ruido de ruidos, entretelas de pandero,

32 Cervantes, Novelas ejemplares, fol. 2r.

${ }^{33}$ La castañuela es «lo mismo que castañetas, aunque más usado hoy entre los cortesanos» (Aut, vol. 2, 1729, fol. 221).

34 Palatín, Diccionario de música, 1990, p. 49.

${ }^{35}$ Ver también la nota al v. 142 en la edición utilizada (pp. 234-235).

36 Esquivel Navarro, Discursos sobre el arte de danzado, 2003, p. 249. En el mismo tratado hay un romance referente a un ensamble de muchos instrumentos de vena popular: «El villano, y la pandorga / y danza de cascabel / todos juntos en mal hora / arredro vayan, Amen» (p. 204). 
liga de todo danzante, manillas de morteruelos, joyeles de los caballos, hábito de caballeros...

(vv. 163-168)

Los últimos dos versos remiten a la usanza medieval de los caballeros de portar cascabeles «no solo para adornar el petral y la grupa de sus caballos, sino para armar ruido y aterrar a los enemigos» ${ }^{37}$.

En escena, otro ladrón hermana al pandero a la «danza fregaril» (v. 143), en el sentido de «Fregar. Estregar una cosa contra otra con fuerza» $(A u t)$. El instrumentista lleva a cabo una presentación llena de elementos populares:

$$
\begin{aligned}
& \text { Éste es el supleguitarras, } \\
& \text { el son de los zagalejos, } \\
& \text { el reclamo de las Maya } \\
& \text { el bullicio gitanesco, } \\
& \text { el apodo de los tontos, } \\
& \text { el susurro... }
\end{aligned}
$$

Al ser de vibraciones (aunque de membrana y en raras ocasiones de cuerda), el pandero puede ser comparado con la guitarra. La bulla, alegría y celebración al son de cualquier tipo de pandereta están siempre asociadas a este «instrumento rústico de que suelen usar en los bailes en las aldeas», y de aquí la mención a los zagales y al festejo de la Invención de la Santa Cruz en el mes de mayo, «formado de un cuadro de madera, cubierto de pergamino o piel muy lisa por ambos lados, y en el hueco están unas cuerdas cruzadas, y en ellas cascabeles o sonajillas, que le hacen resonar mucho». En sentido metafórico se le llama pandero "al hombre necio y que habla mucho con poca substancia» $(A u t)^{38}$.

Torrente porta las sonajas, vinculándolas al oficio y movimientos del cedacero (v. 140) en la misma línea en que Guzmán de Alfarache, al hablar de las «mujeres de buen parecer», comenta que «no hay za-

37 Pedrell, Diccionario técnico de la música, p. 72.

${ }^{38}$ Ver también Palatín, Diccionario de música, 1990, pp. 80-81. 
patero de viejo que no les acometa ni queda cedacero que no las haga bailar al son de la sonaja» (Guzmán de Alfrache, p. 561). Un cedazo es un utensilio compuesto de un aro y de una tela que sirve para limpiar y separar lo sutil de lo grueso $(A u t)$. El alcalde le quita a Torrente las sonajas,

gusto de los blancos, regocijo de los negros, socorro de villancicos, de las pandorgas, estruendo, chillido de portugueses...

(vv. 179-183)

La integración y aceptación popular es evidente en este tono. El Libro de cuentas de la catedral de Salamanca nos habla de un grupo de baile para la fiesta del Corpus de 1507, compuesto por «tres personajes, y una dama y tres serranas, y tres negros y una negra que dancen y bailen y cuatro portugueses que bailen a son de unas sonajas y tres labradores ${ }^{39}$. Sobre la alta voz en tiple hay una clara alusión a la folía: "cierta danza portuguesa de mucho ruido; porque ultra de ir muchas figuras a pie con sonajas» (Cov.).

Chilindrina vuelve a las tablas con el silbatillo, similar al «habla de jilgueros ${ }^{40}$; menciona su función de señuelo en el campo; así como la de «verdugo de las comedias». También habla del regodeo que provoca el silbato en las fiestas de toros y de una función más práctica al ser «bocina de salteadores» (vv. 186-189).

Lorenzo reaparece en escena, pero ahora con la guitarra, calificada como:

el ser de los tonos,

la ganancia de los ciegos,

la ronda de los veranos,

la esclava de los barberos,

${ }^{39}$ Ver García Fraile, 2005, p. 332.

${ }^{40}$ En la tercera silva del poema burlesco, Lope de Vega escribe que el cazador de pájaros con oído atento ve "caer el inocente / jilguero, que los dulces silbos siente» (La gatomaquia, vv. 153-154). 
el aparador de cuerdas,

la lengua...

(vv. 191-196)

A finales del siglo XVI la guitarra había incorporado un quinto orden de cuerdas y es ésta la que conocemos como guitarra española, descrita por el tratadista Juan Carlos Amat en 1596, quien enseña a templar y tañer rasgado todos los puntos naturales y bemoles. En el instrumento de cuerda punteada se pone cualquier tono por medio de una tabla (tablatura), con la cual, según Amat, cualquiera puede cifrarlo, tañer y cantar por doce $\operatorname{modos}^{41}$. La atribución al barbero parece obscura, mas es un tópico bien conocido en la época. Vicente Suárez de Deza hace hablar a uno del mismo oficio que antepone las folías en vez de «barbas y sangrías» ${ }^{42}$.

Con el hurto de la guitarra llegamos al fin de la secuencia. El alcalde Oruga resalta lo grotesco del atuendo de Rechonchón quien no se defiende y dice que su vestido parece «Picota con pesos falsos»" 43 . "¿Y qué habéis de hacer con eso?» (vv. 203-204), inquiere Oruga. Y aquí reside, a mi entender, el significado último y punto clave del entremés. El beneficio de las acciones de Rechonchón descansa en su respuesta: "Herme las fiestas yo solo, / pues todas las danzas tengo" (vv. 205-206). Ganancia equivalente es la adquirida por el auditorio por medio de los tonos cantados y el desfile de instrumentos. La coreografia de las expectativas es aquella que utiliza la experiencia sonora del público para confirmar sus predicciones, añadir información a éstas y así predisponerlo para espectáculos posteriores. La acumulación de danzas y mudanza de aparejos musicales debe entenderse según los movimientos hechos en la voz, en las danzas, en el arreglo al tañido de los instrumentos, así como en la variedad de los afectos involucrados. En este sentido, durante la revista de instrumentos cada

41 Amat, Guitarra española, 1980. El versado en el arte guitarrista «tiene por oficio tocar la guitarra en las compañías de comediantes» (Aut).

42 El mismo personaje asegura que «Tocar una guitarra es lo primero / que ha de saber hacer el buen barbero» (Suárez de Deza, Entremés del barbero para Palacio, vv. 10-12).

43 Picota: «rollo u horca de piedra que suele haber a las entradas de los lugares, adonde ponen las cabezas de los ajusticiados o los reos a la vergüenza» $(A u t)$.Ver también Díez Borque, 1983, p. 241. 
uno funciona como machina, «ingenio o artificio dispuesto para ejecutar alguna cosa con mayor facilidad, prontitud o actividad» $(A u t)^{44}$.

En suma, hemos venido delineando al componente musical de Los instrumentos dentro de una integración del espectáculo, basada en la memoria, en la experiencia auditiva y en la ordenación emocional de las secuencias sonoras que se ajusta al consenso del público. El mismo contexto teatral soporta la interacción entre afectos y sonidos donde los patrones de respuesta reducen la operación mental del auditorio y ubican a éste en un espacio físico, sea el corral de comedias o la calle donde la corporalidad es el primer filtro. Cuando suena algo fuera de las expectativas del auditorio, el cuerpo sirve de referencia, filtra y actúa en tiempo y espacio simultáneos al estímulo. La perspectiva corporal sitúa sonidos u objetos reales, pero también ayuda a formar ideas abstractas. Mediante una secuencia sonora se desprende el punto de vista de su escucha, así como un reforzamiento de la conciencia de grupo, consecuencia extraordinaria de la puesta en escena de varios indicios musicales, del manejo de emociones y de la coreografia de expectativas. El (re)conocimiento de los sonidos sucesivos provoca la identificación de un "sentido de sí mismo» más estable conforme avanza la pieza ${ }^{45}$. La experiencia sonora del público es producto de las operaciones realizadas por la memoria mediante los cuales se categorizan ciertos hechos aprendidos y se ponen en relación con otros recuerdos para organizar el pasado y anticipar el futuro.

Es así que el auditorio procesa toda la información extraída de la realidad a partir del cotejo con su propia experiencia como oyente y la almacena en el territorio de su intimidad; el cual a pesar de ser un ámbito reservado para un individuo, se conforma a partir de sentimientos de emociones - en la terminología de Damasio- que constituyen la perspectiva única de una comunidad en relación a su forma de experimentar la realidad. El entremés calderoniano de Los instrumentos ofrece claves para la interpretación de las comedias o autos que amenizaba, así como pistas para reconstruir el contexto sonoro común para el espectador del siglo Xvir. Para que los estímulos sonoros activen los circuitos neurales de los oyentes, los significados y en sí, las respuestas cognitivas asociadas a la música han sido distri-

\footnotetext{
${ }^{44}$ Ver las diferentes acepciones de mudanza.

${ }^{45}$ Ver Damasio, 1999, pp. 94-95.
} 
buidas dentro de las coordenadas de la fiesta teatral, en donde los dramaturgos, directores, compositores e intérpretes manipulan las expectativas y diseñan su coreografía. 


\section{Bibliografía}

Alemán, M., Guzmán de Alfarache, ed. B. Brancaforte, Madrid, Akal, 1996. Амat, J. C., Guitarra española, ed. M. Hall, Monaco, Chanterelle, 1980.

Asensio, E. Itinerario del entremés, desde Lope de Rueda a Quiñones de Benavente, Madrid, Gredos, 1971.

Bermudo, J., Comienza el libro primero de la declaración de instrumentos, Osuna, Juan de León, 1549.

Calderón de la Barca, P., Los instrumentos, en Entremeses, jácaras y mojigangas, ed. E. Rodríguez y A. Tordera, Madrid, Castalia, 1982, pp. 226-239.

- Teatro cómico breve, ed. M. ${ }^{\mathrm{a}}$ L. Lobato, Kassel, Reichenberger, 1989.

- En la muerte de la señora doña Inés Zapata, en Selección de poemas, Alicante, Biblioteca Virtual Miguel de Cervantes, 2000.

- Deposición a favor de los profesores de la pintura, ed. E. Wilson, Alicante, Biblioteca Virtual Miguel de Cervantes, 2009.

Calvin, W., "The Trilogy of Homo seriatim: Language, Consciousness, and Music», en The Cerebral Symphony: Seashore Reflections on the Structure of Consciousness, New York, Bantam Books, 1989, pp. 277-300.

Caramuel, J., Primer cálamo de Juan Caramuel. Tomo II: Rítmica, ed. I. Paraíso, Valladolid, Universidad de Valladolid, 2007.

Casares Rodicio, E. "La música religiosa en el barroco europeo», en La música en el barroco, ed. E. Casares Rodicio, Oviedo, Universidad de Oviedo, 1977, pp. 51-86.

Cervantes, M., Novela de la Gitanilla, en Novelas exemplares, Madrid, Juan de la Cuesta, 1613, fols. 1r-38r.

Covarrubias, S. de, Tesoro de la lengua castellana o española, Madrid, Luis Sánchez, 1611.

Damasio, A., El error de Descartes: la razón de las emociones, Santiago de Chile, Andrés Bello, 1996.

- The Feeling of What Happens: Body and Emotion in the Making of Consciousness, New York, Harcourt Brace, 1999.

- En busca de Spinoza: neurobiología de la emoción y de los sentimientos, Barcelona, Crítica, 2005.

Diccionario de AUtOridAdes, Madrid, Imprenta de la Real Academia Española, 1726-1739, 6 vols.

Díez Borque, J. M. a , «Estudio preliminar», en P. Calderón de la Barca, Una fiesta sacramental barroca: loa para el auto "Entremés de los instrumentos", Madrid, Taurus, 1983, pp. 7-120.

Donald, M., A Mind so Rare: The Evolution of Human Consciousness, New York, Norton, 2001.

Esquivel Navarro, J., Discursos sobre el arte del danzado, ed. L. Brooks, Lewisburg, Bucknell University Press, 2003. 
García Fraile, D., «Las calles y las plazas como escenario de la fiesta barroca", en Música y cultura urbana en la edad moderna, ed. A. Bombi, J. Carreras y M. Marín, Valencia, Universidad de Valencia, 2005, pp. 307-334.

GeErtz, C., Local Knowledge: Further Essays in Interpretive Anthropology, New York, Basic Books, 1983.

Huron, D., Sweet Anticipation: Music and the Psychology of Expectation, Cambridge, The MIT Press, 2006.

Hutchins, E., Cognition in the Wild, Cambridge, The MIT Press, 1995.

Leibnitz, G., "On the Ultimate Origin of Things», en Philosophical Works of Leibnitz, ed. G. Duncan, New Haven, Morehouse and Taylor, 1908, pp. 106-113.

Locke, J., Ensayo sobre el entendimiento humano, ed. E. O’Gorman, México, Fondo de Cultura Económica, 1999.

López Calo, J., «La música religiosa en el Barroco español: orígenes y características generales», en La música en el barroco, ed. E. Casares Rodicio, Oviedo, Universidad de Oviedo, 1977, pp. 147-190.

Lorente, A., El porqué de la música, en que se contiene los cuatro artes de ella, canto llano, canto de órgano, contrapunto, y composición, Alcalá de Henares, Imprenta de Nicolás de Jamares, 1672.

Pagels, H., The Dreams of Reason: The Computer and the Rise of the Sciences of Complexity, New York, Simon and Schuster, 1988.

Palatín, F., Diccionario de música (Sevilla, 1818), ed. Á. Medina, Oviedo, Universidad de Oviedo, 1990.

Pedrell, F., Diccionario técnico de la música, Barcelona, I. Torres Oriol, 1894. Pollin, A., "Calderón de la Barca and Music: Theory and Examples in the Autos (1675-1681)", Hispanic Review, 41.2, 1973, pp. 362-370.

Sage, J., "The Function of Music in the Theatre of Calderón», en The Comedias of Calderón, vol. 19, ed. D. W. Cruickshank y J. E. Varey, London, Tamesis, 1973, pp. 209-223.

SuÁrez de Deza, V., Teatro breve, ed. E. Borrego, Kassel, Reichenberger, 2000, vol. 2.

Suldivan, H., «Review: Pedro Calderón de la Barca, Entremeses, jácaras y mojigangas", Hispanic Review, 53.3, 1985, pp. 369-371.

Turner, M., The Literary Mind, New York, Oxford University Press, 1996. VegA, L. de, La gatomaquia, ed. C. Sabor de Cortázar, Madrid, Castalia, 1982. 